\title{
Popularização das Ciências e Jornalismo Científico: possibilidades de Alfabetização Científica
}

\author{
Popularization of Science and Scientific Journalism: possibilities of Scientific \\ Literacy
}

\author{
Alessandro Augusto Barros Façanha' \\ Flavia Chini Alves ${ }^{2}$
}

\section{Resumo}

Este estudo evidencia a interseção entre a educação científica e a comunicação na perspectiva da popularização das ciências a partir das evidências produzidas em uma coluna específica de um jornal de grande circulação da cidade de Teresina/PI. As discussões se basearam na análise do conteúdo realizado no âmbito das aulas de ciências em uma escola da educação básica com estudantes ensino fundamental, onde foram utilizados os textos jornalísticos com temáticas diversas que envolviam a ciência e o cotidiano no intuito de compreender a interpretação dos textos e a relação com o contexto da divulgação científica e da cidadania. Utilizou-se da análise do conteúdo e estratificaram-se as respostas em categorias de natureza conceitual e de aplicação das temáticas. As análises demonstram que os textos de divulgação científica tem uma contribuição em relação à popularização das ciências, fomento ao debate em sala de aula, incremento didático nas aulas de ciências, apesar de sua inserção ainda incipiente no contexto da educação científica. Entretanto, os resultados da investigação denotam a dificuldade enfrentada pelos alunos em compreender o texto de divulgação em sua abrangência conceitual e resolutiva de problemas do cotidiano, bem como o distanciamento entre o contexto das ciências no seu escopo teórico e sua apresentação em situações do cotidiano, apesar disso, os textos de divulgação corroboraram como uma via importante de inserção real no processo de alfabetização científica e promoção de cidadania.

Palavras chave: ensino de ciências; alfabetização científica; divulgação científica.

\section{Abstract}

This study evidences the intersection between scientific education and communication in the perspective of the popularization of sciences based on the evidence produced in a specific column of a large circulation newspaper of the city of Teresina / PI. The discussions were based on the analysis of content carried out in the context of science classes in a school of basic education with elementary students, where journalistic texts were used with diverse themes that involved science and daily life in order to understand the interpretation of texts And the

\footnotetext{
${ }^{1}$ Universidade Federal do Rio Grande do Norte - UFRN | abfacanha@gmail.com

2 Universidade Federal de Alagoas - UFAL | chiniflavia@live.com
} 
relationship with the context of scientific dissemination and citizenship. The analysis of the content was used and the answers were stratified into categories of conceptual nature and application of the themes. The analyzes show that the texts of scientific dissemination have a contribution in relation to the popularization of sciences, fomentation to the debate in the classroom, didactic increment in the classes of sciences, in spite of their insertion still incipient in the context of scientific education. However, the results of the research denote the difficulty faced by the students in understanding the text of dissemination in their conceptual comprehension and resolution of daily problems, as well as the distance between the context of the sciences in their theoretical scope and their presentation in everyday situations, Despite this, the texts of divulgation corroborated as an important way of real insertion in the process of scientific literacy and promotion of citizenship.

Keywords: science teaching; scientific literacy; scientific divulgation.

\section{Introdução}

A divulgação científica consiste em uma área da comunicação voltada a divulgar informações sobre a amplitude da ciência, tecnologia, inovação e conhecimento científico com intuito difundir informações relevantes no percurso de seus desenvolvimentos, aplicações e atualidades que aproximem o cidadão a estes contextos. Ao longo do tempo atendeu a interesses e motivações diversificados, os quais, correlacionados ao contexto histórico denotam essas variações em decorrência dos pressupostos e paradigmas vigentes na ciência, na cultura e nos meios de comunicação de cada época (RUBLESCKI, 2009; MASSARANI, BAUER e AMORIM, 2013; MASSARANI e MERZAGORA 2014).

Na perspectiva da educomunicação encontra-se o jornalismo científico cujo objeto consiste em divulgar informações sobre a amplitude da ciência e tecnologia, com intuito popularizar as informações acerca das descobertas científicas, novas tecnologias, inovação e resultados de pesquisas aplicadas ao cotidiano, em uma linguagem acessível a população.

O Jornalismo Científico atua como um dos elementos de ligação entre a comunidade científica ou tecnológica e a sociedade em geral, fazendo de domínio público, em seu sentido mais amplo, os avanços desses campos. Ao profissional que nele atua cabe conciliar o papel informativo/disseminador de Informação Científica e Tecnológica com as regras, princípios e rotinas produtivas da imprensa (RUBLESCKI, 2009).

Atrelando informação e conhecimento científico na perspectiva da informalidade do discurso torna a ciência acessivel e através de um processo de educomunicação científica promove cidadania e protagonismo social, pois revela conteúdos de relevância para o cotidiano em uma comunicação acessível e promotora do direito à informação garantindo inserção, informação e cidadania. Dessa maneira, o processo de divulgação científica ganha status diferenciado na vida das pessoas interferindo no dia a dia das pessoas, nos seus hábitos, rotinas e, sobretudo, no modo de vida, de pensar e de agir.

(...) a mídia, hoje, coloca a agenda de discussão. Segundo pesquisas, ao redor de $82 \%$ dos temas e assuntos que são falados no trânsito, no trabalho, em casa, nos encontros sociais etc. são colocados à discussão pela mídia; ela determina, até certo ponto, o que deve ser falado e discutido (GUARESCHI, 2010). 
Nesse sentido a difusão de ciências e seu processo de divulgação amplia o conceito de comunicação adquirindo uma denominação educomunicativa, de forma que, para além do aspecto da informação, amplia o espectro da comunicação e cria ecossistemas de comunicação e educativos que possibilitam o crescimento e desenvolvimento dos indivíduos e da coletividade (SOARES, 2004).

Em se tratando do jornal impresso, além de uma tendência das grandes publicações nas últimas décadas (NUNES, 2003; BUENO, 2010), a linguagem proposta no jornal, sobretudo em colunas específicas, propicia uma fidelização do leitor, pois apesar do advento de outras mídias e da internet, de acordo com dados da Secretaria de Comunicação Social - SECOM - o jornal ainda é uma fonte de informação veiculada para o público, sobretudo em função da linguagem e do acesso (BRASIL, 2014).

Este estudo traz um recorte de um projeto de divulgação científica realizado em um jornal de grande circulação na capital de Teresina o qual foi inserido como proposta didáticopedagógica em uma escola de educação básica em aulas de ciências no intuito de observar a interface entre a popularização das ciências e a percepção de jovens em idade escolar acerca dos temas e de sua inserção no processo de alfabetização científica, percebido como processo de compreensão e aplicação dos conceitos científicos em situações problema do cotidiano (OCDE, 2012).

\title{
O Jornalismo Científico, Popularização das Ciências e cidadania
}

\author{
Texto científico e jornalístico no contexto da Educação Científica.
}

Debates relacionados à forma pela qual o conhecimento científico deve ser apreendido pela população, de maneira a não simplesmente acumular informações, mas usá-las para tomar decisões são foco do debate nas últimas décadas. Tais discussões ultrapassam o contexto meramente informativo e adquirem nuances educativas que visam um processo de educação científica através do incremento de propostas formais e não formais que contribuam e transcendam o espaço escolar na direção de um processo de alfabetização científica (KRASILCHIK e MARANDINO, 2007).

Nesse contexto as ciências adquirem uma dimensão conceitual e epistemológica que além de informar o cidadão torna premente, a partir dos aspectos conceituais de ciência, inserir o indivíduo no modelo de participação social, resolução de problemas, pensamento crítico e leitura dom mundo a partir dos conceitos científicos.

Salienta-se que a ciência deve deliberar sobre questões sociais onde os futuros cidadãos possam se educados para serem consumidores críticos do conhecimento científico, pois a literacia científica só faz sentido se fizer parte de um conhecimento que subsidie o pensamento crítico (TENREIRO-VIEIRA e VIEIRA, 2014).

A educação em ciências numa perspectiva de literacia científica poderá ajudar os indivíduos a compreender os problemas do mundo e a contribuírem para a construção de propostas de resolução e cursos de ação que permitam minorá-los. Poderá, igualmente, estimular as pessoas a usar informação e formas de pensar, incluindo o pensar de forma crítica, para a tomada de decisão esclarecida e racional, para a resolução de problemas e para a participação ativa e responsável numa sociedade democrática (TENREIROVIEIRA E VIEIRA, 2014). 
Nesse sentido a ampliação do arcabouço didático-metodológico ganha destaque em pesquisas que evidenciam as novas perspectivas da educação científica, com apelo à incorporação de novas mídias, tecnologias e inserção nas temáticas de ciência e inovação. Nessa perspectiva, a utilização de textos de divulgação em diferentes formatos vem sendo apontado como um percurso possivel e promissor (SILVA e ALMEIDA, 2005; ROCHA, 2012; CALDAS 2010).

Especificamente em relação ao texto jornalístico amplia-se a sua repercussão na sala de aula em função de sua relevância na formação da opinião, o destaque cotidiano e atual de sua linguagem e a forte correlação que o jornal permite ao contexto dos seus leitores em função de sua natureza cultural e coloquial (CALDAS, 2006).

Atrelar dessa forma a educação científica, a popularização das ciências e a inserção das mídias no meio escolar através de textos jornalísticos e científicos, contribui para além da formação de leitores, na construção de cidadãos críticos, conscientes e protagonistas de seus papeis na sociedade, uma vez que:

A formação de cidadãos, atributo da escola, passa hoje obrigatoriamente pela habilitação do cidadão para ler os meios de comunicação, sabendo desvelar os implícitos que a edição esconde; sendo capaz de diferenciar, entre os valores dos produtos dos meios, aqueles que estão mais de acordo com a identidade de sua nação; reconhecendo os posicionamentos ideológicos de manutenção do status quo ou de construção de uma variável histórica mais justa e igualitária. E, para isso, a escola não pode esquecer-se do ecossistema comunicativo no qual vivem os alunos. Ou seja, ou a escola colabora para democratizar o acesso permanente a esse ecossistema comunicativo ou continuará a operar no sentido da exclusão, tornando maiores os abismos existentes. (BACCEGA, 2003)

Além disso, apropriar-se das informações divulgadas em textos jornalísticos e científicos, desenvolvendo uma leitura crítica sobre o mesmo é parte do processo de educação científica, além de fazer parte do escopo legal que regimenta e educação básica brasileira que prevê, dentre outras questões relacionadas ao desenvolvimento de competências e habilidades cognitivas, a aprendizagem leitora e sua interpretação do cotidiano a partir de seu pleno domínio.

O artigo 32, inciso I, da Seção III do Ensino Fundamental, da Lei de Diretrizes e Bases da Educação Nacional (LDB), que tem como um de seus objetivos "O desenvolvimento da capacidade de aprender, tendo como meios básicos o pleno domínio da leitura, da escrita e do cálculo", nessa perspectiva, não apenas no âmbito do ensino da língua portuguesa, mas a partir de uma dinâmica interdisciplinar, a leitura passa a conduzir uma ação de natureza cultural e social capaz de capilarizar a inserção do indivíduo enquanto cidadão em exercício.

O acesso à leitura - um bem cultural - deve ser oportunizado a todos os cidadãos. Ler a palavra escrita, a palavra oral, a palavra não dita, implícita no contexto ou em uma imagem, e depreender o sentido que emana de fatores linguísticos e extralinguísticos torna-se prioridade na escola e fora dela. O analfabeto, hoje, não é simplesmente aquele que não sabe ler ou escrever, mas o que não compreende os textos que o circundam (GHILARDI, 1999).

Ademais, os novos objetivos para o processo de alfabetização científica envolvem a capacidade ao debate, o questionamento e leitura crítica do mundo, nesse sentido, a possibilidade de se promover este processo a partir de situações contextualizadas, de 
problematizações e inserção de informações que congreguem a ciência a tecnologia e a sociedade, utilizando textos jornalísticos e científicos, permitem gerar discussões e questionamentos, como uma alternativa a fim de refletir sobre as implicações dos conteúdos das ciências no dia a dia dos cidadãos (RUBLESCKI, 2009; ZAMBONI, 2001; MASSARANI e BUYS, 2008).

\section{O texto de divulgação científica nas salas de aulas de Ciências}

As aulas de ciências devem formar cidadãos aptos ao modelo de sociedade atual, não apenas indivíduos capazes de/(aptos) a lidar com os conceitos científicos em aulas de ciências, mas cidadãos preparados a resolver problemas, ler o mundo e interpretar fenômenos científicos em seu contexto político, econômico e social (CHASSOT, 2010).

As aulas e as modalidades de se abordar as ciências devem preconizar ações de educação para o cotidiano e alinhar à educação científica como uma atividade que extrapole a sala de aula e mobilize atitudes de cidadania e leitura do mundo (TEIXEIRA, DE MORAES AGUDO e TALAMONI, 2016).

Para tanto é necessário fugir de padrões universalizantes e tradicionais no aspecto da leitura do mundo, das metodologias e dos materiais didático-pedagógicos. Nesse aspecto a utilização de textos da mídia mobiliza a sala de aula à medida que possibilita articular o conteúdo abordado nos textos com informações que permeiam o cotidiano dos alunos, tornando-se um recurso de ensino, motivador para aprofundamento dos assuntos veiculados (TERRAZAN e GABANA, 2003).

Pesquisas da área de educação em ciências já discorrem sobre a eficácia de textos de divulgação científica em aulas de ciências como instrumentos capazes de complementar o uso de materiais educativos tradicionais, como os livros didáticos (SILVA; ALMEIDA, 2005; ABREU et al., 2007; QUEIROZ et al., 2012). Tais pesquisas enfocam, dentre outras análises, a importância que deve ser dada a práticas em sala de aula que, além de facilitarem a incorporação do saber científico, contribuem para a formação de habilidades, competências científicas e hábitos que se perenizam mesmo após o egresso da educação formal. Observando os próprios normativos da educação brasileira é possível observar considerações nesse sentido:

Lidar com o arsenal de informações atualmente disponíveis depende de habilidades para obter, sistematizar, produzir e mesmo difundir informações (...). Isso inclui ser um leitor crítico e atento das notícias científicas divulgadas de diferentes formas: vídeos, programas de televisão, sites da Internet ou notícias de jornais (BRASIL, 1999, p.27).

Além disso, extrapolando os aspectos legais e as diretrizes da educação científica, a incorporação de textos de divulgação científica na escola é o primeiro passo para a leitura do mundo, pois é essencial no exercício cotidiano de cidadania possibilitando além da leitura do mundo a construção de narrativas próprias (CALDAS, 2006).

A escola, portanto, deve cumprir seu papel de formadora de leitores e, para isso, não dispensar a colaboração que os meios de comunicação podem dar. A cada debate promovido, novos caminhos surgirão e provocarão a necessidade de novas discussões. O importante é a troca de experiências e o momento de reflexão sobre o trabalho realizado. (GHILARDI, 1999).

Destacando as considerações de Martins et al. (2001), sugere-se que estratégias didáticas que possibilitem o contato com diferentes tipos de textos científicos que expressem diversas 
nuances e formas de argumentação favoreçam o desenvolvimento de habilidades de leitura, domínio de conceitos, habilidades linguístico-cognitivas como argumentação, leitura crítica além de subsidiar estratégias de pensar cientificamente. Assim, passar a conhecer uma variedade de tipos de textos científicos, desde reportagens de mídia até originais de cientistas, é condição para tornar-se um participante da cultura científica (DE ABREU FERREIRA e QUEIROZ, 2012).

Nesse sentido, a utilização do texto de divulgação possibilita não apenas o entendimento dos conteúdos, contextualizando-os, mas também contribui para a educação científica e tecnológica dos alunos e que, assim, estarão preparados para analisar de forma crítica o que acontece ao seu redor, contribuindo para que reflitam sobre a não neutralidade da ciência e da tecnologia (NIEZER, SILVEIRA e SAUER, 2012).

A coluna Educando Com(ns)Ciências no Jornal O Dia - um espaço de ciência e cidadania

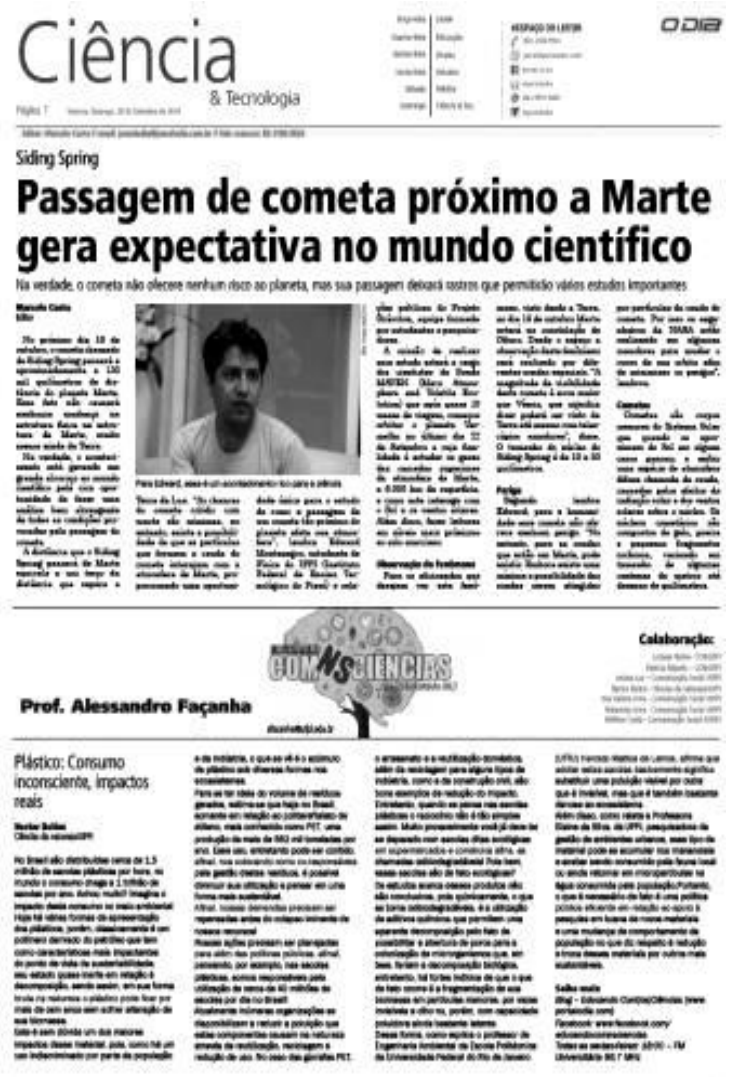

Figura 1: Layout da página da coluna no jornal impresso

O objeto desta investigação consistiu de uma coluna de publicação dominical destinado à divulgação científica que surgiu com desdobramento de um projeto institucional vinculado a uma parceria entre o corpo editorial e os coordenadores do projeto de educomunicação da Universidade Federal do Piauí.

Inicialmente a proposta contemplava programas de radiofusão com a temática das ciências, sustentabilidade, ecologia e cidadania. Institucionalmente, o projeto Educando Com(ns)Ciências, surge em resposta ao Edital Proext/SeSU/MEC de 2014, na área temática da Comunicação, sendo encaminhado para concorrência nacional do referido edital via Sistema de 
Informação e Gestão de Projetos do Ministério da Educação (http://sigproj1.mec.gov.br/) e contemplado com recursos para execução no período de Janeiro a Dezembro de 2014.

Como ampliação do projeto inicial estabeleceu-se uma parceria interinstitucional entre a UFPI e o Jornal impresso O Dia, de Teresina, onde se organizou uma coluna semanal no caderno de Ciência \& Tecnologia destinada a textos jornalísticos de divulgação científica produzidos pela equipe do projeto inicial que contava com professores e alunos das ciências da natureza e bolsistas da comunicação social.

Os textos da coluna eram organizados em função das demandas locais debatidos nas reuniões de pauta da equipe e apresentavam uma construção atrelada ao contexto social, cultural, político inserido em abordagens de ciência, tecnologia e inovação a partir de uma perspectiva de divulgação científica.

Por se tratar de um ambiente de divulgação de comunicação, atrelavam aspectos tecnológicos, sociais e culturais que configuravam uma demanda sociocientífica aos textos, em virtude de ser uma forma de alinhar o discurso à lógica multimodal de informação e dinamismo cultural com inserção em segmentos gerais e específicos como o de estudantes e professores no intuito de possibilitar inserção no contexto educacional (DE MORAES, NAMAN, e DARSIE, 2016)

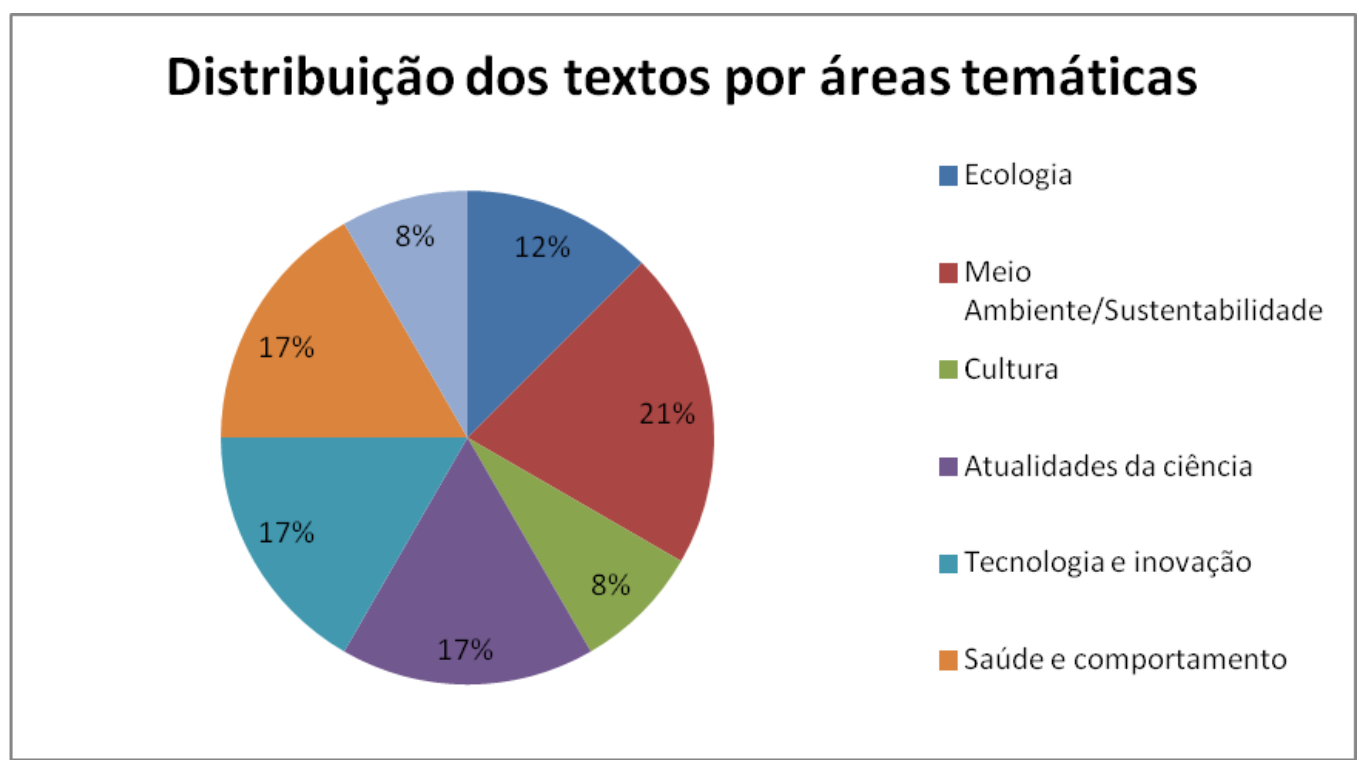

Gráfico 1: Distribuição percentual dos textos da coluna por área do conhecimento

Por se tratar de uma ação que envolvia a Universidade pública e seus agentes, havia uma preocupação em atrelar os textos ao material didático pedagógico das escolas de educação básica a fim de possibilitar inserção do material como acervo das aulas de ciências por meio de projetos de parceria universidade/escola como o Programa Institucional de Iniciação à Docência - PIBID - no qual os futuros professores executavam ações de docência assistida.

A coluna teve uma duração de 48 semanas e contribuiu ao fim de sua publicação com textos em grandes áreas do conhecimento e bastante diversificada, de acordo com o gráfico 1.

Para efeito deste estudo foram analisados três colunas com as temáticas distribuídas em diferentes áreas do conhecimento de acordo com interesse do pesquisador e em consonância com atividades desenvolvidas no âmbito de aulas de ciências em uma escola do município de Teresina, em aulas de ciências do $8^{\circ}$ ano do ensino fundamental, pormenorizadas na metodologia do trabalho. 


\section{Aspectos Metodológicos da Investigação.}

A partir de uma perspectiva de investigação de um fenômeno a fim de elucidar suas relações com os sujeitos ou mesmo na tentativa de obter interpretações acerca de um fenômeno em relação a sua abrangência, postula-se que a descrição do objeto e suas nuances seja a melhor proposta de analise.

Nesse sentido, em consonância com as proposições de Gil (2010), o presente estudo opta por uma abordagem descritiva de investigação, no sentido de que as pesquisas descritivas possuem como objetivo a descrição das características de uma população, fenômeno ou de uma experiência. No caso específico tendo por pauta delinear as impressões dos estudantes em aulas de ciências acerca do papel dos textos de divulgação científica, caracterizar o conteúdo dos textos em função da sua abordagem conceitual e os reflexos que os mesmos implicaram na construção de atitudinal dos sujeitos.

A parte descritiva da pesquisa foi realizada tendo com vinte cinco alunos do $8^{\circ}$ ano do Ensino Fundamental com idades entre 13 e 14 anos, do período diurno, de uma escola pública no bairro Água Mineral, na cidade de Teresina/PI. A análise dos textos seguiu as premissas da análise do conteúdo de Bardin (2009), na qual se categorizou as narrativas em função dos conhecimentos conceituais e atitudinais próprios do ensino das ciências.

Para a coleta dos dados com os estudantes utilizou-se do questionário que continham, além dos textos das colunas a serem analisadas, perguntas sobre: a interpretação conceitual do texto, reflexões cotidianas frente à problemática dos textos e nível de percepção cognitiva em relação à linguagem dos textos. Além disso, com o intuito de se traçar um perfil geral dos leitores em relação aos hábitos, cultura leitora e perfil demográfico, foram realizadas coletas gerais em função dessas variáveis.

Os textos selecionados para a investigação foram escolhidos a partir das temáticas abordadas nas aulas de ciências e em consonância com os interesses expostos dos participantes ao serem convidados a participarem da pesquisa. Foram selecionados três textos, cujos temas foram: Água: Renovável deve ser nossa atenção; Plástico: Consumo inconsciente, impactos reais e Maconha: o que a ciência nos mostra?

Em relação aos textos selecionados os questionamentos seguiam os critérios relacionados aos objetivos descritos, nesse sentido aos alunos eram feitos os seguintes questionamentos: identificação do assunto que tratava o texto; identificação de um problema cotidiano relacionado ao contexto; importância do texto na resolução de algum problema real e relação do texto com as aulas de ciências.

Quanto à participação dos estudantes foram garantidos os preceitos éticos de investigações dessa natureza tendo os participantes assinado um termo de consentimento com garantia de anonimato, exclusão da amostra em qualquer momento da pesquisa e acesso aos resultados. O mesmo trâmite se deu em relação à escola e seus funcionários.

\section{Resultados e discussão}

Antes da apresentação dos resultados específicos de cada coluna/temática serão apresentados os dados referentes à caracterização da amostra de participantes a fim de se traçar um perfil dos estudantes em relação ao gênero, faixa etária e hábitos relacionados à leitura, acesso à informação e utilização de meios de comunicação para atualizações cotidianas. 
A amostra $(n=25)$ era composta de $32 \%$ de meninas $(n=8)$ e $68 \%$ de meninos $(n=17)$ com faixa etária compreendida entre 13 a 14 anos; em relação ao conhecimento prévio da coluna de divulgação em análise, 100\% da amostra respondeu desconhecer a existência da mesma, apesar de $20 \%(n=5)$, relatarem ter acesso à jornal e utilizarem desse meio para informação esporádica, o que coincidiu com o percentual de respostas positivas em relação à utilização do jornal e das revistas para informação do cotidiano.

Esses dados preliminares acerca do perfil dos alunos e seus hábitos de leitura e meios de informação denotam um nível preocupante em relação ao uso de jornal e mídias impressas em geral como forma de informação, pois a maioria contingencial dos estudantes $(70 \%, n=17)$, relata não ter como hábito à leitura de jornais e revistas.

Confrontando os dados com as atuais pesquisas acerca do índice de leitura no Brasil, segundo as quais, o hábito leitor vem crescendo e hoje, segundo dados da pesquisa "Retratos da leitura no Brasil" do Instituto Pró-livro (FAILLA, 2014), que realiza levantamentos junto ao Ministério da Cultura, 56\% da população brasileira tem o hábito de ler, observa-se um perfil destoante em razão da média de leitores da investigação (11\%) estar muito distante dos achados da pesquisa.

Ainda nesse tocante, os dados deste estudo tornam-se ainda mais preocupantes se comparados aos dados do nível de escolaridade, acesso à educação e índice de analfabetismo revelado pela Pesquisa Nacional de Amostras de Domicílio do Instituto Brasileiro de Geografia e Estatística (IBGE, 2014), a PNAD 2015, que aponta para um incremento da escolarização em indivíduos entre 6 a 14 anos, com estimativa de acesso da ordem de 98,5\% e redução considerável de analfabetos considerando o comparativo do início dos anos 2000, com uma configuração de apenas 8,3 \% na faixa até 13 anos.

Diante disso, tendo como perspectiva ações de redução desses indicativos, inspirados em projetos na área de leitura em geral (CALDAS, 2006; FERREIRA e DIAS, 2002) e em situações específicas das ciências como base para o desenvolvimento da habilidade leitora (LIMA e AZEVEDO, 2014; SANMARTI, 2007; IZQUIERDO e SANMARTI, 2000), acredita-se que o investimento em projetos de leitura na escola, ampliação de acervo, estratégias metodológicas de incentivo à leitura nas aulas de outras disciplinas que não apenas nas de línguas e literatura, além de parceiras com bibliotecas e programas de extensão universitária poderiam ser uma via de minimizar essa realidade.

Em relação aos resultados relacionados às colunas específicas do jornal, as análises serão apresentadas por texto temático, assim, observou-se que:

\section{Acerca do texto "Água, renovável deve ser a nossa atenção".}

Em relação à análise do texto em função de seu conteúdo é possível caracterizá-lo como um texto de divulgação que trouxe como discurso principal o conceito inerente à racionalidade em função da utilização da água enquanto recurso finito e de responsabilidade coletiva.

Identifica-se o contexto da sustentabilidade enquanto discurso narrativo e uma tentativa de alertar para uma tomada de decisão em relação à utilização do recurso desde medidas simples até complexas como por parte do poder público. Como suporte para os argumentos do texto traz dados e opiniões de especialistas representantes de órgãos de manejo e controle, entretanto, a partir de uma linguagem coloquial e objetiva.

Na visão dos alunos inseridos no estudo, após a leitura do texto e a contextualização com as aulas de ciências acerca da temática, as impressões foram as seguintes: em relação à caracterização do conteúdo do texto em relação aos conceitos, $42,1 \%$ dos alunos $(n=8)$ trouxe 
no conteúdo de suas respostas conclusões superficiais do texto disseram se tratar de desperdício de água, porém não fizeram relação com problemas do seu cotidiano e sequer mencionaram aonde seria possível retirar ideias do texto para resolução de problemas do dia a dia, além disso, disseram não entender o significado de algumas palavras utilizadas como, por exemplo, onerosa, na frase "(...) é fato que os recursos hídricos, apesar de sua renovabilidade, devem ser encarados e tratados como finitos e de manutenção onerosa". Além disso, para 56\% dos alunos ( $n=14)$, não foi possível correlacionar no texto aspectos das ciências estudados na escola, embora para um percentual ainda maior $76 \%(n=19)$, o texto poderia ser utilizado nas aulas de ciências em assuntos de biologia, pois trazem informações importantes. Diante dos dados, várias são as conjecturas no campo educacional e da comunicação no âmbito da divulgação científica valendo ressaltar algumas correlações com evidências de estudos e interpretações de pesquisadores das áreas correlatas. Em relação à superficialidade das interpretações é fiável perceber que, apesar de negativo o dado se assemelha com muitas interpretações e resultados de estudos na área da proficiência em Ciências e até mesmo de leitura.

Tomando como referência os dados acumulados do Programa Internacional de Avaliação de Estudantes (2009, 2012, 2015), o PISA, coordenado pela Organização para Cooperação e Desenvolvimento Econômico - OCDE - o nível de compreensão conceitual dos estudantes brasileiros de idade compatível aos do estudo é limitado no que tange à explicação dos fenômenos científicos, correlação com as contextualizações e incompatível com suas aplicações em fenômenos do cotidiano (INEP, 2009; 2012; 2015).

Além disso, em relação à dificuldade de interpretação da leitura em decorrência do vocabulário ou afins, é perceptível a lacuna ainda existente em relação ao letramento em nossas escolas, para ter ideia, apesar do acesso e do número de analfabetos ter reduzido (PNAD, 2015), ainda há no Brasil aproximadamente um contingente expressivo de analfabetos funcionais que não compreendem o sentido de um texto (RIBEIRO, 2006). Dados do IBGE de 2009 mostravam um percentual de 20,3\% em relação à população alfabetizada (IBGE, 2009).

No entanto, apesar dos resultados é possível inferir também a importância dada ao texto e as informações trazidas a partir das impressões dos alunos face o poder de contribuição e possibilidade de inserção em aulas de ciências.

\section{Plástico: consumo inconsciente, impactos reais}

Diferente do texto sobre a água a narrativa do conteúdo do texto sobre os plásticos traz mais o cunho conceitual e recorre ao discurso dos conceitos científicos específicos como ponto de partida para o entendimento do assunto, como quando explicita a definição de plástico e a diferença entre o plástico não biodegradável do seu oposto. Nesse sentido o texto incorpora uma narrativa mais técnica apesar de, assim como no primeiro texto analisado, também retomar o discurso da responsabilidade coletiva no manejo e utilização dos recursos. Semelhante ao primeiro faz correlações com as problemáticas ambientais e recorre ao apelo da reflexão acerca do papel que deve ser exercido pelo cidadão no gerenciamento da poluição advinda desse material, inserindo uma narrativa de contexto político no que tange à tomada de decisão em relação ao cotidiano e às ações de cidadania.

Para os alunos do estudo o texto já apresentou mais relação com o cotidiano, onde $80 \%$ $(n=20)$ relatou em suas respostas que a leitura poderia ajudar na forma de proceder no dia a dia em relação aos plásticos tendo inclusive uma parcela importante da amostra $48 \%(n=12)$, 
relacionando o conceito de oxibiodegradabilidade com o que já observaram no cotidiano com sacolas largadas no meio urbano, nesse ponto, foi possível observar que o texto sensibilizou maior percentual de alunos, 92\% ( $n=23)$, no sentido de remetê-lo a um conteúdo capaz de ajudar a resolver problemas do dia a dia.

Entretanto, para 48\% ( $n=12)$ o texto também trouxe um vocabulário desconhecido que dificultou o entendimento, para esses alunos, o termo latente, na frase "(...) há fortes indícios de que o que de fato ocorre é a fragmentação de sua biomassa em partículas menores, por vezes invisiveis a olho nu, porém, com capacidade poluidora ainda bastante latente", prejudicou o entendimento por classificarem o termo como difícil de entender.

Além disso, dada a dimensão das extrapolações do texto, apesar de não serem objeto deste estudo, vale ressaltar as observações surgidas para além do conteúdo do texto por parte de $36 \%$ dos estudantes $(n=9)$, os quais disseram que apesar do texto mostrar os prejuízos dos plásticos que eles são contrários à retirada das "sacolinhas" dos supermercados.

Observando as respostas e fazendo correlação com as evidências e os estudos relacionados observa-se, assim como no texto sobre água, a dificuldade da linguagem na compreensão do conteúdo o que corrobora não só para o entendimento deficitário como para a não propagação das ideias do texto (NALOM, SOARES e CÁRNIO, 2015) o que no caso específico de textos de divulgação científica tem um duplo prejuízo, pois além de reduzir a reverberação do conteúdo textual implica no distanciamento dos indivíduos com o contexto da popularização das ciências.

Outro ponto que merece destaque é o da relação dos hábitos do consumidor brasileiro e a cultura da descartabilidade exposta pela opinião dos estudantes em relação à não dispensar o uso das "sacolinhas". Tal fato reitera a necessidade de mudança de hábito e um repensar o modelo de consumidor, uma vez que a atitude precisa ser incorporada em benefício da coletividade e não visando a comodidade (LORENZETT, 2013).

Nesse sentido, apesar de nas últimas décadas ter sido investido em campanhas, cartilhas e em políticas de redução, inclusive na mídia, o papel da escola, dos projetos integrados e da educação ambiental enquanto projeto educacional são vias de construção de um novo modelo e de um novo perfil de consumo (FABRI e SILVEIRA, 2010).

Nessa perspectiva, no entanto ressalta-se o papel preponderante da comunicação aliada à ciência, sobretudo via divulgação científica, pois como a própria pesquisa revela na opinião dos alunos, o papel e a importância dessa categoria de produção são importantes na tomada de decisão e no repensar atitudes.

\section{Maconha: o que a ciência nos mostra?}

O texto sobre a maconha, diferentemente dos anteriores, trouxe um discurso bem mais coloquial e informativo do que conceitual, apesar da preocupação de caracterizar a planta e sua denominação, não trouxe subsídios conceituais e taxonômicos próprios da linguagem bilógica ou botânica, a intenção do texto, talvez em virtude de sensibilizar o leitor para uma reflexão do contraponto ao discurso marginal e repressor que cerca o senso comum das substâncias ilícitas, foi o de alertar para as reações frente o uso e a comparação com outras substâncias lícitas.

Ficou exposto um conteúdo de caráter informativo e analítico acerca da opinião polarizada acerca de algumas místicas em relação ao uso da maconha, embora trouxesse visões menos estereotipadas dos seus efeitos nocivos, fez referência a essas consequências de modo a não caracterizar um texto em apologia ao uso da droga, por fim, finaliza o discurso com uma 
mensagem em tom educativo sobre a importância da ciência na investigação das substâncias psicoativas e reforçando a tendência de se buscar hábitos saudáveis fora do uso de drogas.

Em relação às análises das respostas dos estudantes observou-se uma maior empatia em relação ao texto dado que $92 \%$ dos alunos $(n=23)$ responderam que o texto contribuiu muito para o entendimento de problemas do cotidiano e que gostariam de ver o assunto do texto debatido nas aulas e na escola, sendo importante ressaltar um dado para além das perguntas, mas que veio a tona em $20 \%$ dos questionários $(n=5)$, que foi a ideia de que o texto contrapôs as ideias trazidas em palestras na escola. Atento a esse dado se investigou as ultimas intervenções da escola nessa temática e se descobriu que as referidas palestras eram em geral proferidas por grupamentos da polícia militar ou por representantes da área de saúde ligadas ao modelo de intervenção psiquiátrica de internação compulsória de dependentes químicos.

Tal fato possibilitou reflexões acerca do discurso ainda muito estereotipado e caricatural com que os usuários de drogas ou mesmo o uso de drogas ainda é percebido no meio social a ponto de inferirmos o quanta as políticas públicas ainda permanecem com discurso repressor e pouco educativo.

Ressalta-se, entretanto, em consonância com estudos que trazem essa temática para o campo educativo, como destaca Moreira, Silveira e Andreoli (2006), que esta perspectiva contradiz os pressupostos e os referenciais dos processos que envolvem ações de educação e saúde, sobretudo à luz do enfrentamento da dependência química e da atual política de redução de danos.

O que os alunos relatam vai de encontro com as propostas internacionais de enfretamento às drogas, as quais preveem uma atuação preventiva e educativa em detrimento à repressão, controle da força, por violência ou aparato moral (FIGUERADO e GREDORI, 2002; CARLINICOTRIM e PINSK, 2013).

Ao contrário dos outros textos analisados, não houve relato de dificuldade em relação à linguagem e ao vocabulário empregado denotando assim a empatia e a dimensão de aceitabilidade e familiaridade com a temática.

\section{Conclusão}

Um estudo dessa natureza, por mais que tenha um direcionamento inicial acaba, por ventura da imersão no contexto para além da comunicação e do texto em si, norteando muitas perspectivas de convergência, assim, não em um propósito conclusivo, pois em educação de discurso comunicativo as conclusões são quase sempre relativizadas, mas com o intuito de se traçar generalidades e propostas.

Dessa maneira vale enfatizar através dos resultados, a importância da inserção de textos de divulgação científica no contexto das pessoas, sobretudo no ambiente escolar, pois, para além de uma proposta curricular tácita, promove o debate, o pensamento crítico, a não linearidade das aulas e do conteúdo disciplinar como norteador do conhecimento, logo, os resultados e o cotidiano na escola nos evidenciam que as propostas de popularização das ciências contribuem com a formação e com o processo de alfabetização científica podendo ser uma via de construção de conhecimento e cidadania.

Além disso, no campo da comunicação, a divulgação científica amplia o discurso para além do texto e possibilita o diálogo com os contextos plurais e coletivos. No âmbito da escola constitui uma via de construção humana e de cidadania, pois promove o pensar e o produzir opiniões e argumentos. 
Portanto o estudo demonstra que é possível se fazer comunicação e ciência com eficiência, interação e protagonismo e que a divulgação científica apesar de não corresponder (e nem pretende) a uma panaceia no campo da formação de uma cultura científica é precisamente uma via a ser investidos esforços no contexto escolar.

\section{Referências}

BARDIN, Laurence. Análise de conteúdo. Lisboa: Edições, v. 70, 2009.

BRASIL. Presidência da República. Secretaria de Comunicação Social. Pesquisa brasileira de mídia 2015: hábitos de consumo de mídia pela população brasileira. - Brasília: Secom, 2014

BUENO, Wilson Costa. Comunicação cientifica e divulgação científica: aproximações e rupturas conceituais. Informação \& Informação, v. 15, n. 1 Especial, p. 1-12, 2010.

BUENO, Wilson da Costa. Os novos desafios do jornalismo científico. In: Atas do VII Congresso Iberoamericano de Jornalismo Científico. Argentina, 2001.

CARLINI-COTRIM, Beatriz; PINSK, lana. Prevenção ao abuso de drogas na escola: uma revisão da literatura internacional recente. Cadernos de Pesquisa, n. 69, p. 48-52, 2013.

CALDAS, Graça. Mídia, escola e leitura crítica do mundo. Educação \& Sociedade, v. 27, n. 94, p. 117-130, 2006.

CALDAS, Graça. Mídia, Educação Científica e Cidadania: a experiência das revistas Eureca e ABC das Águas. IN: PINTO, Gisnaldo Amorim. Divulgação Científica e Práticas Educativas. Curitiba: Editora CRV, p. 149-166, 2010.

DE ABREU FERREIRA, Luciana Nobre; QUEIROZ, Salete Linhares. Textos de Divulgação Científica no Ensino de Ciências: uma revisão. Alexandria: Revista de Educação em Ciência e Tecnologia, v. 5, n. 1, p. 3-31, 2012.

DE MORAES, Mariuce Campos; NAMAN, Diana Claudia; DARSIE, Marta Maria Pontim. Formação docente relacionada com questões sociocientíficas: complexidade, contribuições e limitações de uma prática educativa. Amazônia: Revista de Educação em Ciências e Matemáticas, v. 12, n. 23, 2016.

FABRI, Fabiane; SILVEIRA, Rosemari Monteiro Castilho Foggiatto. O ensino de Ciências nas séries iniciais: uma reflexão e uma proposta de trabalho a partir da temática Sacolas Plásticas. Programa de Pós-Graduação em Ensino de Ciência e Tecnologia, Universidade Tecnológica do Paraná, 2010.

FAILLA, Zoara. Retratos da leitura no Brasil 3. São Paulo: Imprensa Oficial do Estado de São Paulo, 2014.

FIGUEIREDO, Regina Maria Mac Dowell de; GREDORI, Rosana. Prevenção ao abuso de drogas em ações de saúde e educação: uma abordagem sociocultural e de redução de danos. IN: Prevenção ao abuso de drogas em ações de saúde e educação: uma abordagem sociocultural e de redução de danos. NEPAIDS, 2002.

FERREIRA, Sandra Patrícia Ataíde; DIAS, M. G. B. B. A escola e o ensino da leitura. Psicologia em Estudo, v. 7, n. 1, p. 39-49, 2002.

GUARESCHI, Pedrinho A. Mídia e cidadania. Conexão-Comunicação e Cultura, v. 5, n. 09, 2010. 
GIL, Antonio Carlos. Métodos e técnicas de pesquisa social. São Paulo: Atlas, 2010.

IBGE. Pesquisa Nacional por Amostra de Domicílios 2014. Disponível em: http://www.ibge.gov.br/home/estatistica/populacao/trabalhoerendimento/pnad2014/default_sin tese.shtm. Acesso em: 10 Fevereiro de 2017.

IBGE. Pesquisa Nacional por Amostra de Domicílios. Tabela de indicadores sociais de 2001 a 2009. Disponível em: http://seriesestatisticas.ibge.gov.br/series.aspx?t=taxaanalfabetismo\&vcodigo=PD384. Acesso em: 10 Fevereiro de 2017.

IZQUIERDO, Mercé; SANMARTÍ, Neus. Enseñar a leer y a escribir textos de ciencias de la naturaleza. In: JORBA, Jaume; GÓMEZ, Isabel; PRAT, Ángels. Hablar y escribir para aprender. Madrid: Síntesis, 2000. p. 181-193.

LIMA, José Luiz de Vasconcelos; AZEVEDO, Rosa Oliveira Marins. Jogos didáticos como estratégia para o desenvolvimento da competência leitora/escritora no ensino de ciências. Revista Areté - Revista Amazônica de Ensino de Ciências, v. 7, n. 12, 2014.

LORENZETT, Juliana Benitti et al. Sacolas plásticas: uma questão de mudança de hábitos. Revista Monografias Ambientais, v. 11, n. 11, p. 2446-2454, 2013.

MASSARANI, Luisa; BAUER, Martin W.; AMORIM, Luís. Um raio X dos jornalistas de ciência: há uma nova 'onda' no jornalismo científico no Brasil?.Comunicação \& Sociedade, v. 35, n. 1, p. 111129, 2013.

MASSARANI, Luisa; MERZAGORA, Matteo. Socially inclusive science communication. JCOM: Journal of Science Communication, v. 13, n. 2, 2014.

MOREIRA, Fernanda Gonçalves; SILVEIRA, Dartiu Xavier da; ANDREOLI, Sérgio Baxter. Redução de danos do uso indevido de drogas no contexto da escola promotora de saúde. Ciência \& Saúde Coletiva, v. 11, n. 3, p. 807-816, 2006.

NALOM, A. F. O.; SOARES, A. J. C.; CÁRNIO, M. S. A relevância do vocabulário receptivo na compreensão leitora. Rev CoDAS, v. 27, n. 4, p. 333-8, 2015.

NUNES, J. H. A divulgação científica no jornal: ciência e cotidiano. IN: GUIMARÃES, E. Produção e circulação do conhecimento. Campinas: Pontes, 2003.

OCDE, Fundación Santillana. Relatório Nacional PISA 2012: resultados brasileiros. Brasília; INEP, 2012.

RIBEIRO, Vera Masagão. Analfabetismo e analfabetismo funcional no Brasil. IN: SANTOS, E. Reescrevendo a Educação. São Paulo: Scipione, p. 26-37, 2006.

ROCHA, Marcelo Borges. O potencial didático dos textos de divulgação científica segundo professores de ciências. Revista Brasileira de Ensino de Ciência e Tecnologia, v. 5, n. 2, 2012.

RUBLESCKI, Anelise. Jornalismo científico: problemas recorrentes e novas perspectivas. Ponto de Acesso, v. 3, n. 3, p. 407-427, 2009.

SANMARTÍ, N. Hablar, leer y escribir para aprender ciencia. IN FERNÁNDEZ, P. (Coord.). La competencia en comunicación lingüística en las áreas del currículo. Madrid: MEC, 2007.

SILVA, HC da; ALMEIDA, M. J. P. M. O deslocamento de aspectos do funcionamento do discurso pedagógico pela leitura de textos de divulgação científica em aulas de física. Revista Electrónica de Enseñanza de las Ciencias, v. 4, n. 3, p. 1-25, 2005. 
TEIXEIRA, Lucas André; DE MORAES AGUDO, Marcela; TALAMONI, Jandira Liria Biscalquini. Análise do processo participativo em projetos ambientais desenvolvidos em um bairro de Bauru/SP. Amazônia: Revista de Educação em Ciências e Matemáticas, v. 12, n. 23, 2016.

TERRAZZAN, Eduardo Adolfo; GABANA, Marciela. Um estudo sobre o uso de atividade didática com texto de divulgação científica em aulas de física. Atas do Encontro Nacional de Pesquisa em Educação em Ciências, v. 4, p. 25, 2003. 